\title{
sciendo
}

\section{Green Practices as a Path towards the Sustainability: Evidence from Portuguese Companies}

\section{Wellington Alves}

Escola Superior de Ciências Empresariais, Instituto Politécnico de Viana do Castelo; ALGORITMI Research Centre, University of Minho; Escola de Engenharia, Depto Produção e Sistemas, Campus de Azurém, Portugal Ângela Silva

Escola Superior de Ciências Empresariais, Instituto Politécnico de Viana do Castelo; Centro de Investigação em Organizações, Mercados e Gestão Industrial (COMEGI), Lusíada University, Portugal

Helena Sofia Rodrigues

Escola Superior de Ciências Empresariais, Instituto Politécnico de Viana do Castelo; Center for Research and Development in Mathematics and Applications (CIDMA), University of Aveiro, Portugal

\section{Abstract}

Background: In the last years, the concept of sustainability has been receiving global attention from academics, the public sector and practitioners. The high level of industrialization has contributed to the increase of environmental impacts on the environment and the society. To give a sustainable answer to the industrial sector, more strategies aimed at reducing the environmental and social impacts should be considered. Objectives: This research aims to evaluate the level of environmental practices in a set of companies from the northern region of Portugal. Methods/Approach: In order to achieve the objective of this research, several steps were taken, and approach is mainly based on an online questionnaire administered in a set of companies. Results: The initial results show that companies are progressing when it comes to the implementation of measures and practices related to sustainability. Conclusions: The study resulted in suggestions for consulted companies, namely the need for effective mechanics to ensure compulsory but expedite environmental procedures along with procedures control, which is a key factor in ensuring sustainable and green practices.

Keywords: green practices, sustainability, Portugal, statistical analysis JEL: L16

Paper type: Case Study

Received: Jan 30, 2020

Accepted: Jul 6, 2020

Citation: Alves, W., Sila, Â., Rodrigues, H. S. (2020), "Green Practices as a Path Towards the Sustainability: Evidence from Portuguese Companies", Business Systems Research, Vol. 11, No. 2, pp. 7-20.

DOI: $10.2478 / \mathrm{bsrj}-2020-0012$ 


\section{Introduction}

At the heart of sustainable development, is the need to build-up initiatives, measures, assessment and monitoring production processes that may cause environmental, social and economic impacts on society. The contribution to the reduction of these impacts could increase the prominence of sustainability in the industrial sector (Khandokar et al., 2009).

Over the last decade, the concept of sustainability has been receiving global attention from academics, public sector and practitioners. Yet, the industrial sector has a long path to go on achieving sustainable process in their industrial processes (Varela et al., 2019). In response to the urgent for sustainability, strategies for environmental and social impacts must be considered. According to OECD (2010, p.4) sustainable strategies are usually based "on the identification and evaluation of criteria that expose potential impacts on the three dimensions of sustainable development, namely, social, economic and environmental". Towards sustainability, sustainable practices have been increasing attention as a powerful driver to achieve sustainaible development. These practices are related to the development of initiatives and policies to guide companies to improvements in their operations. Despite the relevance of the integration of sustainable practices into traditional operations to increase sustainable performance, it is still a barrier for small and medium-sized companies.

It is the case of Portugal, the country is characterized by a large amount of micro, small and medium enterprises (SMEs). Over the last years these companies have increasing awareness of the needs to implementation of sustainable strategies. However, there are still many SMEs which lack resources and capabilities or suffer from inertia in this field, it has been contributing to discourages the intentions to develop sustainable practices. The case of companies operating in the Northern region of Portugal is particularly relevant since studies showing (see Pereira \& Leitão, 2013; European Commission, 2020) that small-scale companies operating is a major issue in the region (PORDATA, 2020). Despite the contribution of these companies for the region, the implementation of sustainable practices persists as a challenge task for these companies (Moreiras, 2010).

Connecting company's activities to their environmental, social and economic impacts, rise the need to create sustainable strategies to decrease its impacts. This paper aims then to answer the following question: Which environmental practices have been adopted by companies operating in the northern region of Portugal? Then, the research aims to analyze the implementation level of practices related to environment in a set of companies from the North of Portugal.

To accomplish the objective of the study, it has conducted a review of the relevant literature relevant to sustainability and environmental practices. Then, the case of companies operating in the Northern region of Portugal was taken as a sample. In summary, taking into consideration that researches addressing sustainable practices in SMEs in the Northern region of Portugal have not been addressed, this paper aims to contribute to new insights on how these companies have been implementing sustainable practices towards sustainability, as well which practices are already implemented.

The paper is organized into five main sections. Pertinent literature focusing on the relevance of the research, discussing sustainability and environmental practices was conducted in Section 2. Then, the research design and methodology chosen are presented in order to assess the environmental management practices in the North of Portugal, in Section 3. Section 4 presents and discusses the main results; highlighting aspects such as enterprise category (micro, small, medium or large) environmental 
policies were analysed. Section 5 presents conclusions and identifies directions for future works. The paper has been presented at SOR 2019 conference (Silva et al., 2019).

\section{Literature overview}

As one of the key document within the scope of sustainability the Bruntland Commission Report defines sustainable development as the capability of the presentday generations to meet their needs without compromising the capacity of the forthcoming generation achieving their needs (World Commission on Environment and Development, 1987). The discussion around sustainability are mainly integrated within companies that already perceived sustainability as important aspects to be taken into account ias a strategy to improve performance (Alves et al., 2018).

In the last few years, sustainability has been seen as a key subject for organizations worldwide; it has been supporting industries towards addressing economic, social and environmental strategies int their production processes, towards sustainable practices (Ching et al., 2014).

Yet, environmental practices have been posted as a key driver for organizations to the development of sustainability. For instance, a work developed by Rashidi and Cullinane (2019) has investigated the role of sustainability on improving operational logistics performance of companies from diferrent countries. Also, Dey et al. (2011) investigated the development of initiatives towards sustainability in the field of supply chain operations, the work identified opportunities for companies regarding the accomplishment of sustainable practices in logistics.

In this context, due to the complexity of supply chains, sustainability has been jumped in the green agenda for all industrial sectors. The need for incorporating sustainable practices focusing on, for instance, the reduction, or even elimination of the negative impacts generated by products and operational processes on the environment has become imperative for all companies worldwide (Bahr and Sweeney, 2019).

The synergy between green practices and sustainability has been driving forces to implementation of sustainable practices in several industrial sectors. The implementation of these initiatives has the potential to increase sustainable results in in industries (Dües et al., 2013). According to Thorlakson et al. (2018) global supply chain plays a critical role in pressing environmental, social and economic stress struggles identified by the United Nations' Sustainable Development Goals (SDGs). The 17 Sustainable Development Goals (SDG) develop by the United Nations, which aims at fostering global sustainable development through economic, environmental and social level, also established that thre is a need for call attention of supply chains to develop sustainable practices, it due to its considerable influence on sustainable development (Thorlakson et al., 2018; Brockhaus et al., 2019). Yet, environmental and social impacts, such as increasing exhaustion of resources, environmental pollution and global warming are increasing the concerns of government, communities and companies to develop actions towards reductions of ecological and social problems (Yildiz Çankaya \& Sezen, 2019).

Responding to calls from the global community, industries have been paid to the environmental impacts originated from their processes and products. Yet, over the last decades, the connection between sustainable development and green business, has gained increasing importance in the literature in the last years. Nonetheless, the dialogue about environmental strategies in small-medium size industrial activities has not yet gained ground. For instance, the work developed by Aldakhil et al., (2018) examines the key determinants of integrated supply chain management for green business growth for BRICS countries (Brazil, Russia, India, and China), considering some 
aspects such as economic growth and environmental policies, the worked showed that those companies (small-medium size industrial) face several challenges, suc as lack of qualified works and financial support when implementing environmental practices.

According to Sharma (2016) green practices serve as a springboard to develop environmental initiatives towards sustainability, also to contribute to competitive advantage for the industrial sector. The authors defend that sustainability has been one of the most important issues for the manufacturing and development of new products. The reduction of environmental impact has been considered as one of the key principle for governments and society (Alves, et al., 2018). It has led companies to go green and reduce the environmental effect caused by its operations, as well meeting sustainability principles (Bathmanathan \& Hironaka, 2016).

As the resources depletion has taken place in the agenda of the modern societies, to meet the society needs but at the same time to minimize the environmental and social impact caused by the industrial sector, it is imperative to companies develop initiatives focusing on green and eco-friendly strategies (Pradeep \& Kuckian, 2017). Due to the possibility to support companies to address environmentally friendly strategies on producing goods and services, green initiatives have been increasing attention within industrial sector. According to Bathmanathan and Hironaka (2016), the use of green practices such as environmental management, development of eco-friendly products, implementation of environment policy and implementation of certification ISO 14001, are some examples of practices which have been supporting companies to shift their business, towards the sustainable agenda.

The concept of green business is not new, but over the last decade has led to the emergence of the development of green practices to meet sustainability. These practices include different areas such as ecological, social and economic. There are several practices that can be followed in a green approach, for instance, 4R's that focus on Reduction, Reuse, Recycle and Recovery; energy saving; green packing; eco-cleaning; eco-labelling; use of renewable resources are examples of green practices adopted by companies towards sustainability (Ahmad, 2016; Čekanavičius, Bazytè \& Dičmonaitè, 2014; Ghisellini et al., 2016).

In spite of all these concerns, a key challenge related to sustainability in the industrial sector remains to the difficulty of applying this concept on their activities, and at the same time, sdemonstrate to managers its contribution for the company, and also for the environment and social aspects. Thorlakson et al. (2018) defend that despite companies have been seen as a source of environmental problems as a result of their production processes, the development of initiatives towards a green supply chain emerges as an alternative to build environmental-friendly practices in the context of the industrial sector.

Under such a background, this paper aims to investigate the level of environmental practices implemented by a set of Portuguese companies, which could contribute to understand the actual scenario of sustainable practices in these companies.

\section{Methodology}

In order to achieve the objective of this research several stages were considered. Figure 1 summarizes the main stages carried out in this research, namely (1) an analysis of the current literature on green and sustainable practices; (2) based on the literature review a questionnaire was designed to addressing issues related to sustainable practices; (3) a case study was chosen as strategy to asses a set of companies focusing on the 02 companies consulted through an online questionnaire (the sample was defined for convenience, due to time and budget constraints) (4); then a 
statistical analysis was performed, and the main results draw, finally conclusions and directions for future works are presented (5).

\section{Figure 1}

Methodological approach

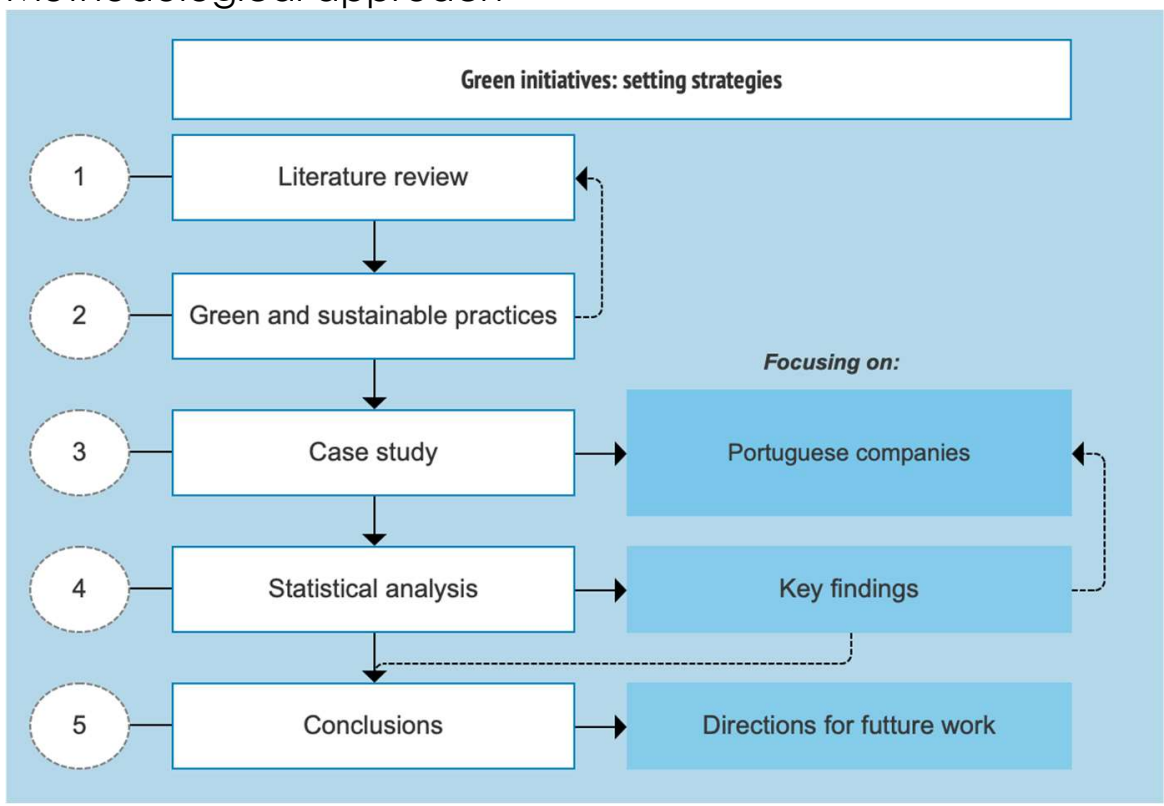

Source: Authors' work

This research was inspired in a previous work developed by Jabbour et al., (2013), where the authors present a survey to asses relationship between lean and green practices in the automobile industry. Here, this research focus on the use of a quantitative method, firstly to asses environmental practices adopted by companies operating in the northern region of Portugal and secondly, to assess its level of implementation. Then, aiming to validate the questionanrire, a fisrt attempt was made, and a pre- test with 10 companies was carried out. Then, an initial sample was defined by convenience and comprised by 700 companies. After screening the intial sample, a an online questionnaire was sent for the 700 companies of our database, and 102 answered with the completely filling, it was taken as a final sample for this research, which mean that the percentage rate is near of $15 \%$.

Table 1

Practices of "Environmental Management" analyzed

\begin{tabular}{ll}
\hline Item & Description \\
\hline EM1 & Clear environmental management policy \\
EM2 & Environmental training for all employees \\
& $\begin{array}{l}\text { 3Rs (Reduction, Reuse and Recycling applied in water, electricity and } \\
\text { paper) }\end{array}$ \\
EM4 & Development of products with lower environmental impacts \\
EM6 & Development of productive process with lower environmental impacts \\
EM7 & Selection of suppliers based on environmental criteria \\
\hline EM8 & Environmental management system (ISO 14001 or others) \\
\hline
\end{tabular}

Source: Authors' work

The questionnaire is divided into two parts: the first one related to the companies' characterization, with questions related to the dimension of the company, number of 
employees; and the second one concerning to measurement of environmental practices as described in Table 1. For the second part, a five-point Likert scale was adopted as a tool to assess the company's performance. The scale comprises five levels of agreement, ranging from (1) "Not implemented" to (5) "Completely implemented". The main findings in this research are discussed in the next chapter. Statistical analysis has been conducted using IBM SPSS version 24.

\section{Results and discussion}

\section{Preliminary analysis}

The proposed questionnaire was developed through the Google Docs platform, in order to be available for the selected companies answer it. The sample (see Table 2) comprise $32.4 \%$ of micro-companies, $25.5 \%$ of small companies, $16.7 \%$ of medium size, and $25.5 \%$ of large companies. Regarding the number of works associated, the results showed that that mostly of the consulted companies have more than three workers. The results also showed that a great number of companies had a turnover (by year), more than 5 million euros (36.3\%).

Table 2

Technical record of participating companies

\begin{tabular}{llllll}
\hline $\begin{array}{l}\text { Dimension on } \\
\text { the company } \\
\text { (number of employees) }\end{array}$ & $\%$ & $\begin{array}{l}\text { Number of } \\
\text { employees } \\
\text { associated } \\
\text { with } \\
\text { logistics }\end{array}$ & & $\begin{array}{l}\text { Turnover } \\
\text { (in euros) }\end{array}$ & $\%$ \\
\hline Micro $(<\mathbf{1 0})$ & 32.35 & {$[0 ; 3)$} & 34.31 & {$[0 ; 100 \mathrm{k})$} & 13.7 \\
\hline Small $(\mathbf{1 0 - 5 0 )}$ & 25.49 & {$[3 ; 6)$} & 20.59 & {$[100 \mathrm{k} ; 250 \mathrm{k})$} & 10.8 \\
\hline Medium $(\mathbf{5 0 - 2 5 0 )}$ & 16.67 & {$[6 ; 9)$} & 5.88 & {$[250 \mathrm{k} \mathrm{500k)}$} & 9.8 \\
\hline Large $(>\mathbf{2 5 0})$ & 25.49 & {$[9 ; 12)$} & 9.80 & {$[500 \mathrm{k} ; 1 \mathrm{M})$} & 10.8 \\
& & {$[12 ; 15)$} & 1.96 & {$[1 \mathrm{M} ; 5 \mathrm{M})$} & 18.6 \\
\hline & & 15 or more & 27.45 & $5 \mathrm{M}$ or more & 36.3 \\
\hline
\end{tabular}

Source: Authors' work

Regarding environmental impacts, it was one of the most important issues related to the production process in the industrial sector. In this direction, green practices are considered as key instruments to ensure the minimization of these impacts (Alves et al., 2019). The results presented in Table 3 summarizes the descriptive statistics associated with eight environmental practices proposed in this research. Results showed that all items were answered using the entire scale, meaning that the level of implementation of the environmental practices from the consulted companies are presented in different stages. These values are in line with the results obtained by Jabbour et. al (2013), where the measures less implemented are the last ones.

The results also showed that the lowest averages are related to environmental management system (EM7) and the selection of suppliers based on environmental criteria (EM6). These values can be explained by the fact that these measures imply more financial for business. The standard deviation does not present great discrepancies between items. Through the alpha analysis of Cronbach, it was obtain values greater than 0.7, which indicates a good internal reliability of the questionnaire. 
Table 3

Descriptive statistics and reliability for environment management practices

\begin{tabular}{lllllllc}
\hline Item & Min & Max & Mean & St. Dev. & Sk & Kurt & $\begin{array}{c}\text { Cronbach's } \\
\text { alpha }\end{array}$ \\
\hline EM1 & 1 & 5 & 3.45 & 1.087 & -0.698 & 0.031 & 0.895 \\
EM2 & 1 & 5 & 3.28 & 1.146 & -0.540 & -0.393 & \\
EM3 & 1 & 5 & 3.40 & 1.017 & -0.649 & 0.262 & \\
EM4 & 1 & 5 & 2.77 & 1.342 & -0.154 & -1.411 & \\
EM5 & 1 & 5 & 2.78 & 1.302 & -0.193 & -1.265 & \\
EM6 & 1 & 5 & 2.51 & 1.391 & 0.193 & -1.416 & \\
EM7 & 1 & 5 & 2.45 & 1.558 & 0.455 & -1.406 & \\
EM8 & 1 & 5 & 2.61 & 1.415 & 0.236 & -1.330 & \\
\hline
\end{tabular}

Source: Authors' work

Following this analysis, the results showed in Figure 2 present the intervals of $95 \%$ of confidence for the average answers of the companies. The circle refers to the mean value, and the interval represents $95 \%$ of the probability that the calculated interval from some future experiment encompasses the true value of the mean of the population. These results confirm the results from Table 3, showing that the first measures have a higher level of implementation, while the latter is still starting.

Figure 2

Confidence interval for environment management practices

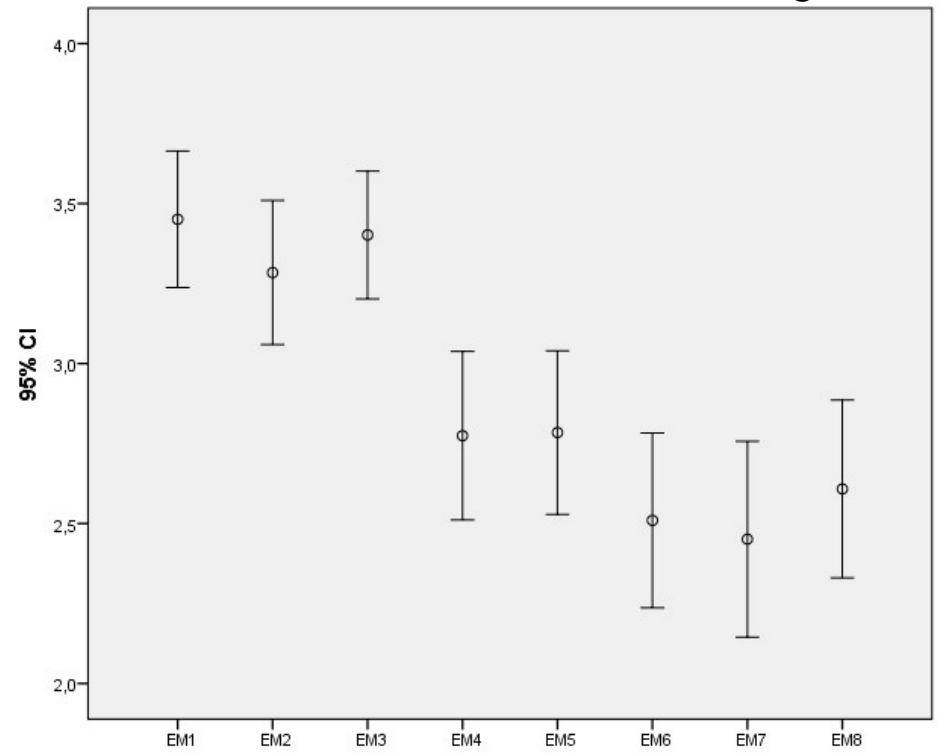

Source: Authors' work

\section{Correlation and Principal Component Analysis}

Table 4 shows the correlation between environmental practices. For the cases of EM4 and EM5, they achieved the highest correlation coefficient (0.816). These relationships are considered as important measures for companies, it because if the company take into account environmental concerns in the design of product/service, the production process could take into account green practices. For the case of EMI and EM2, the results also show a high correlation (0.778). It can be justified due to the fact that these companies have a clear environmental policy in place, also because the employees are involved in the company's policies. For the environmental practices, 
the results showed that in order to develop strategic/finance policies, including green practices, it is considered as an important dimension to be addressed by companies,.

Table 4

Matrix correlation between environment management practices

\begin{tabular}{ccccccccc}
\hline Item & $E M 1$ & EM2 & EM3 & EM4 & EM5 & EM6 & EM7 & EM8 \\
\hline EM1 & 1.000 & & & & & & & \\
EM2 & 0.778 & 1.000 & & & & & & \\
EM3 & 0.578 & 0.674 & 1.000 & & & & & \\
EM4 & 0.403 & 0.467 & 0.553 & 1.000 & & & & \\
EM5 & 0.468 & 0.565 & 0.619 & 0.816 & 1.000 & & & \\
EM6 & 0.436 & 0.548 & 0.497 & 0.635 & 0.662 & 1.000 & & \\
EM7 & 0.621 & 0.570 & 0.390 & 0.385 & 0.380 & 0.372 & 1.000 & \\
EM8 & 0.425 & 0.478 & 0.558 & 0.511 & 0.620 & 0.615 & 0.350 & 1.000 \\
\hline
\end{tabular}

Source: Authors' work

In this section, a Principal Component Analysis was carried out (see Table 5).

Table 5

Principal Component Analysis

\begin{tabular}{|c|c|c|c|c|c|}
\hline \multirow[t]{2}{*}{ Item } & \multirow[t]{2}{*}{ Communalities } & \multicolumn{2}{|c|}{$\begin{array}{c}\text { Loadings } \\
\text { (Varimax rotation) }\end{array}$} & \multirow[t]{2}{*}{$\begin{array}{c}\text { KMO } \\
\text { Measure }\end{array}$} & \multirow[t]{2}{*}{$\begin{array}{c}\text { Bartlett's } \\
\text { test }\end{array}$} \\
\hline & & Component 1 & $\begin{array}{c}\text { Component } \\
2\end{array}$ & & \\
\hline EMI & 0.837 & 0.256 & 0.878 & \multirow{8}{*}{0.855} & \multirow{8}{*}{0.000} \\
\hline EM2 & 0.811 & 0.404 & 0.805 & & \\
\hline EM3 & 0.633 & 0.594 & 0.530 & & \\
\hline EM4 & 0.759 & 0.848 & 0.201 & & \\
\hline EM5 & 0.833 & 0.873 & 0.266 & & \\
\hline EM6 & 0.692 & 0.788 & 0.268 & & \\
\hline EM7 & 0.670 & 0.169 & 0.801 & & \\
\hline EM8 & 0.617 & 0.738 & 0.269 & & \\
\hline
\end{tabular}

Source: Authors' work

The Kaiser-Meyer-Olkin (KMO) and the Bartlett sphericity test indicated that the adequacy of the data for the accomplishment of the factorial analysis (Kline, 2011), since the first result is close to 1, and the Bartlett test lead to the significance level lower than 0.05. Regarding the communalities (after extraction), the analysis showed all variables have values greater than 0.5, which is recommended by Field (2005). Only the first two components have eigenvalues over 1.00, explaining over $70 \%$ of the total variability in the data. The factor loadings were greater than 0.5 for all items, suggesting a good representation of their attributes.

Analysing the loadings of each component, it is possible to confirm that items EM4, EM5, EM6 and EM8 are best represented by component 1, that can call by product and process issues. The items EM1, EM2 and EM4, related to training of the employees. The item EM3 is equal represented in both components; this could be explained by the fact that the 3Rs policy can be considered as part of the environment management system already settled, meaning that they have the system but could not be certificated by the standard ISO 14001 . 


\section{Dimension's analysis by company}

To understand the level of implementation of green measures, it should be more scrutinized if we take the dimension of the company as a factor of analysis. Figure 3 presents the level of environmental management practices of the consulted companies, by the dimension. The results showed that the large ones are at the forefront regarding the implementation of environmental practices.

Figure 3

Average level of environment management practices, by companies' dimension
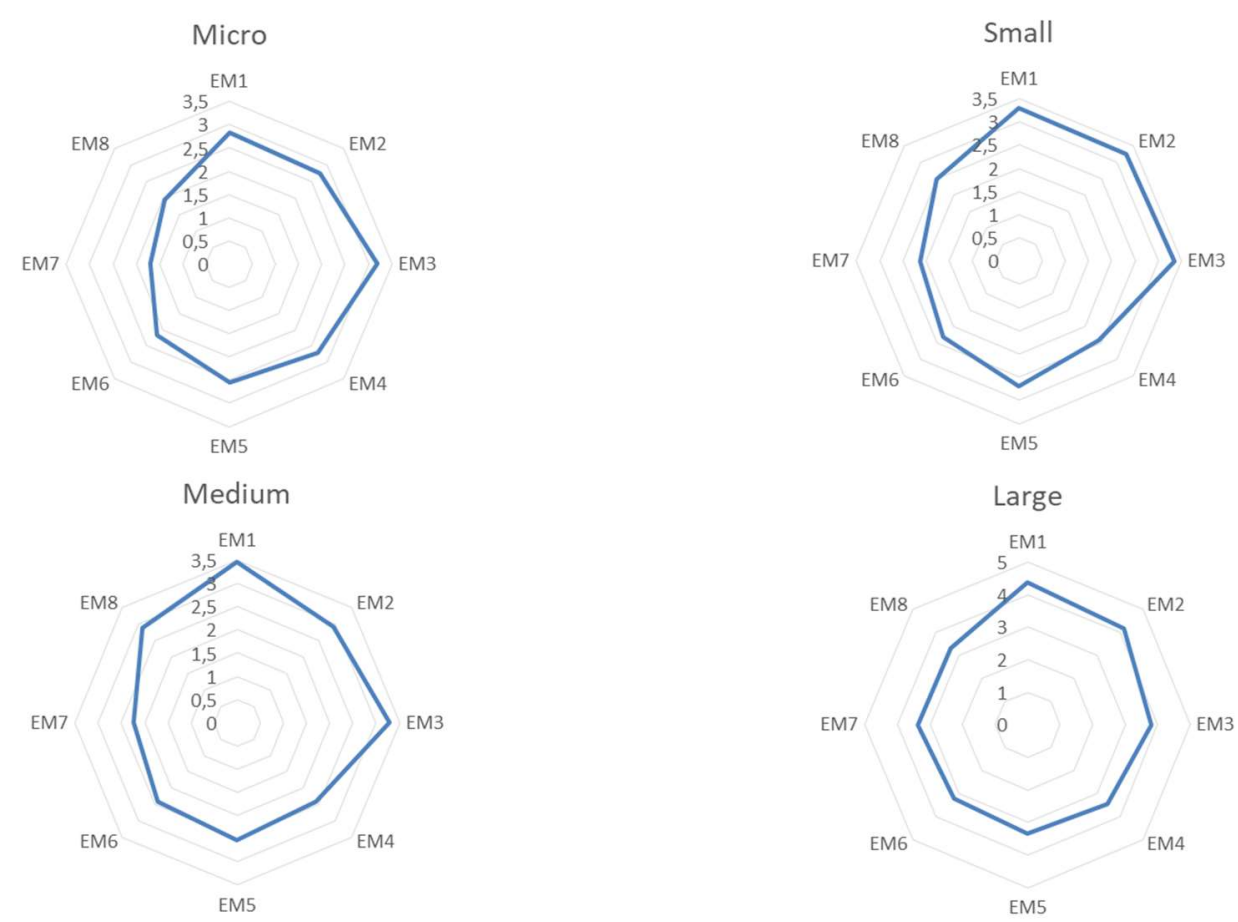

Source: Authors' work

To ensure the impact of these measures, a Kruskal Wallis test was also conducted to examine the differences in practices according to the types of companies inquired (Table 6). At the same time, it was possible to observe that for all companies, the last three environmental practices present the lowest scores; this could be interpreted by the lack of consciousness about the benefits of implementing these practices, and also the scarcity of financial support forwarded to green procedures.

Statistically significant difference exists in almost all the measures, except in EM3 and EM5 (with $\mathrm{p}<0.05$ ); this means that there are significant differences in the stages of companies related to green issues, taking into account the dimension of them (Table 6). This can be explained by the fact that the 3Rs policy (EM3) is already a measure very common and the development of the production process with lower environmental impacts (EM5) is also a great concern related to the reduction of waste. For the items, the hypothesis $\mathrm{HO}$ was rejected in the Kruskall Wallis test, a DunnBonferroni test was performed (see Table 6). This post hoc test reports the results among multiple pairwise comparisons. As expected, the major differences between companies arise in the pairs micro-large and small-large companies. 
Table 6 -Kruskal Wallis Test and Post hoc Dunn-Bonferroni test for green measures (group variable: dimension of the company)

\begin{tabular}{|lllllllll}
\hline Item & EM1 & EM2 & EM3 & EM4 & EM5 & EM6 & EM7 & EM8 \\
\hline Kruskal-Wallis test (sig.) & 0.000 & 0.000 & 0.089 & 0.027 & 0.082 & 0.032 & 0.000 & 0.004 \\
$\begin{array}{c}\text { Dunn-Bonferroni test (sig.) } \\
\quad\end{array}$ & & & & & & & & \\
$\quad$ Micro-Small & 0.308 & 0.481 & --- & 0.496 & --- & 0.678 & 0.329 & 0.166 \\
$\quad$ Micro-Medium & 0.135 & 0.211 & -- & 0.532 & -- & 0.494 & 0.196 & 0.031 \\
\hline Micro-Large & 0.000 & 0.000 & --- & 0.032 & --- & 0.005 & 0.000 & 0.000 \\
$\quad$ Small-Medium & 0.566 & 0.707 & --- & 0.980 & --- & 0.759 & 0.676 & 0.368 \\
$\quad$ Small-Large & 0.000 & 0.001 & --- & 0.008 & --- & 0.023 & 0.000 & 0.042 \\
$\quad$ Medium-Large & 0.002 & 0.001 & --- & 0.017 & --- & 0.087 & 0.002 & 0.364 \\
\hline
\end{tabular}

Source: Authors' work

Finally, for each company, the level of implementation of environmental measures was averaged. Figure 4 shows a summary of the answers: each ball represent the average level of each company in terms of environmental issues. From the results presented, It is possible to observe that most of the large companies are located in the upper right corner, while the micro and small companies have the lowest levels, showing that there is huge progress to be done.

Figure 4

Average level of environment management practices
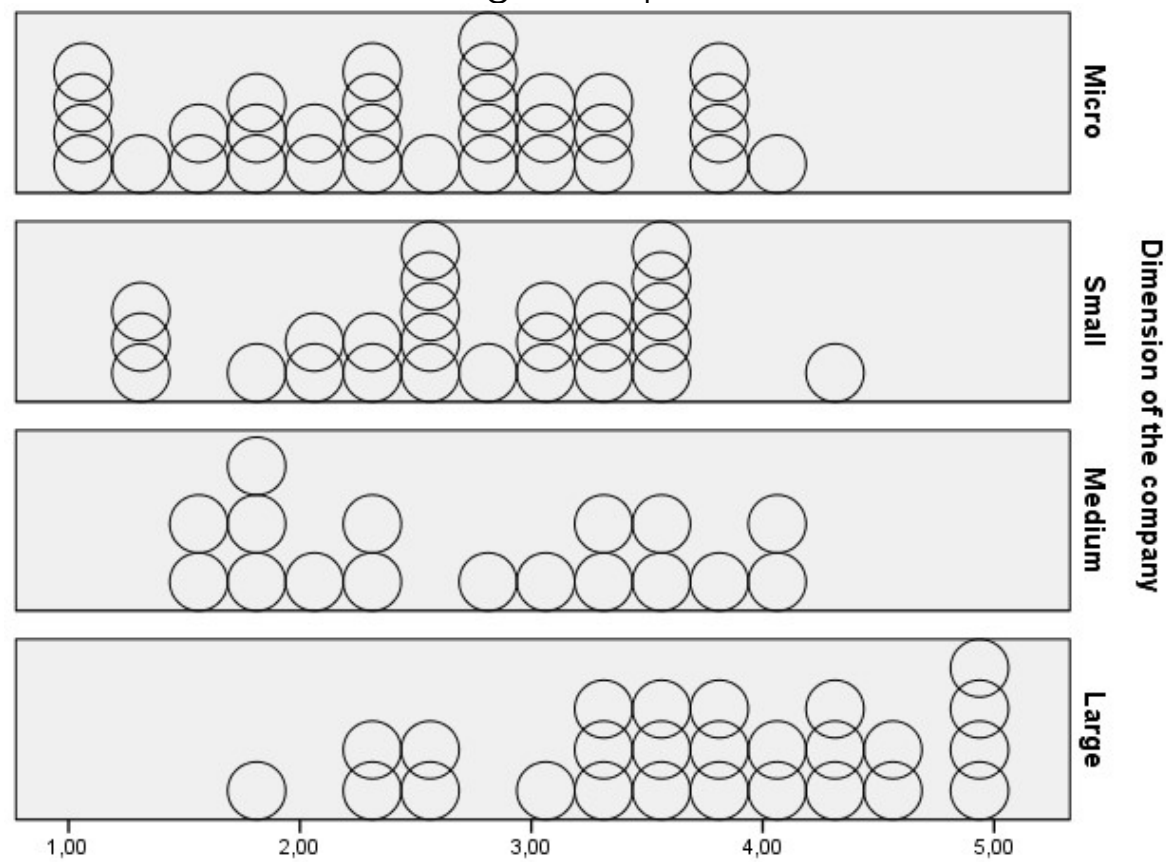

EMmean

Source: Authors' work

\section{Conclusions}

Sustainable practices have become a trend issue to describe activities connected to environmental and sustainable awareness. Such initiatives intend to support companies on reducing their environmental impact. For companies, it can be seen as benefits such as increase profitability, resilience and positive social and environment impacts when addressing green thinking strategies. 
This research contributes then with insights to the current literature on sustainability and green practices within the industrial sector. Also, the analysis of a set of companies consulted, contributes to understand which green practices have been adopted by companies operating in the north of Portugal.

Recognizing the importance of these initiatives we proposed an analysis of the implementation of these practices taking a set of companies as a sample. Results from the literature confirmed that sustainable practices have led companies to develop environmental strategies, such as green initiatives which have been contributing to companies save costs, meet compliance requirements, and also to create a sustainable network among customers.

Regardless of the green practices adopted by the consulted companies, the results showed that there are mostly related to the implementation of 3 Rs initiatives (EM3). Meaning that the use of strategies focusing on reuse, reduction and recycling applied in areas such as water and electricity consumption, were the main focus of companies when developing green practices. Also, practices related to the development of productive processes considering low environmental impacts (EM5) were highlighted in the results. Surprisingly, the results also showed that part of the consulted companies have setted a clear environmental management policy (EM1).

In summary, from the companies' consulted, the research showed that they have a long path to go toward the implementation of sustainable practices, with few exceptions for large companies that have well-defined policies on sustainability field as economic resources to implement it.

Despite being an initial analysis, the results showed that for the consulted companies, the environmental questions are still on a development process. Particularly, small companies face several barriers to implement green operations, especially the ones related to ones that are necessary to obtain certification. To face these barriers, there a positive indication that the Sustainable Development Goals have been supporting companies to developed strategies focusing on economic, environmental and social issues. The strength of green practices could also support the industrial sector on enhancing the SDGs.

The study allowed suggesting some implications regarding the use of green practices in Portuguese' companies. However, the research is not free from limitation. First, the data collection is limited to a region in Portugal. The approach that we present here should be replicated in other regions in the country, to check the green practices and claims news results. Also, the need for a better understanding about causality between green practices and the economic performance of the consulted companies could be addressed as a perspective, both are potential future directions for future developments to be taken in this field.

\section{Acknowledgement}

This research was supported by CAPES and Science Without Borders scholarship, BEX Process 10.190-13-9 (Alves); the FCT - Fundação para a Ciência e Tecnologia, through Project UID/EMS/04005/2019 (Silva); and UIDB/04106/2020 and UIDP/04106/2020 (Rodrigues).

\section{References}

1. Ahmad, M. (2016), "Green business practices: Balancing environment and economic desires", International Journal of Multidisciplinary Research and Development, Vol. 3, No. 5, pp. 266-268. 
2. Aldakhil, A. M., Nassani, A. A., Awan, U., Abro, M. M. Q., Zaman, K. (2018), "Determinants of green logistics in BRICS countries: An integrated supply chain model for green business", Journal of Cleaner Production, 195, pp. 861-868.

3. Alves, W., Ferreira, P., Araújo, M. (2018), "Sustainability awareness in Brazilian mining corporations: the case of Paraíba state", Environment, Development and Sustainability, Vol. 20, No. 1, pp. 41-63.

4. Alves, W., Silva, A., Rodrigues, H. S. (2019), "Sustainable practices: an analysis of Portuguese companies' In 15th International Symposium on Operational Research SOR'19, 25-27 September, Slovenian Society Informatika, Bled, Slovenia, pp. 341-346.

5. Bahr, W., Sweeney, E. (2019), "Environmental sustainability in the follow-up and evaluation stage of logistics services purchasing: perspectives from UK Shippers and 3PLs', Sustainability, Vol. 11, No. 9, 2460.

6. Bathmanathan, V., Hironaka, C. (2016), "Sustainability and business: What is green corporate image?", IOP Conference Series: Earth and Environmental Science, Vol. 32, No. $1,012049$.

7. Brockhaus, S., Petersen, M., Michael Knemeyer, A. (2019), "The promise: signaling sustainability in supply chain relationships', in Logistik im Wandel der Zeit - Von der Produktionssteuerung zu vernetzten Supply Chains (Changing times - from production control to networked supply chains), Springer Fachmedien Wiesbaden, Wiesbaden, pp. 629-645.

8. Čekanavičius, L., Bazytè, R., Dičmonaitè, A. (2014), "Green business: challenges and Practices", Ekonomika, Vol. 93, No. 1, pp. 74-88.

9. Ching, H. Y., Gerab, F., Toste, T. H. (2014), "Scoring sustainability reports using GRI indicators: a study based on ISE and FTSE4Good price indexes', Journal of Management Research, Vol. 6, No. 3, p. 27-48.

10. Dey, A., LaGuardia, P., Srinivasan, M. (2011), "Building sustainability in logistics operations: a research agenda', Management Research Review, Vol. 34, No. 11, pp. 1237-1259.

11. Dües, C. M., Tan, K. H., Lim, M. (2013), "Green as the new Lean: how to use Lean practices as a catalyst to greening your supply chain", Journal of Cleaner Production, Vol. 40, pp. 93-100.

12. European Commission. (2020), "The Northern Region of Portugal", available at: https://ec.europa.eu/growth/tools-databases/regional-innovationmonitor/region/portugal/continente/norte (Januar 30, 2020)

13. Field, A. (2005), Discovering Statistics Using SPSS (2nd ed.), Sage, London.

14. Ghisellini, P., Cialani, C., Ulgiati, S. (2016), "A review on circular economy: the expected transition to a balanced interplay of environmental and economic systems", Journal of Cleaner Production, Vol. 114, pp. 11-32.

15. Jabbour, A. B. L. D. S., Jabbour, C. J. C., Freitas, W. R. D. S., Teixeira, A. A. (2013), 'Lean and green?: evidências empíricas do setor automotivo brasileiro" (Lean and green ?: empirical evidence from the Brazilian automotive sector), Gestão \& Produção, Vol. 20, No. 3, pp. 653-665.

16. Khandokar, F., Price, A., Paranagamage, P., Mourshed, M., Austin, S., Moobela, C. (2009), "Barriers to the adoption of sustainability assessment tools in strategic decision making", in Horner, M., Price, A., Bebbington, J., Emmanuel, R. (Eds.), 2nd International Conference on Whole Life Urban Sustainability and its Assessment, 22-24 April, Loughborough University, Loughborough.

17. Kline, R. B. (201 1), Principles and Practice of Structural Equation Modeling (3rd ed.). Guilford Press, New York.

18. Moreiras, N. (2010), "Corporate social responsibility: an empirical analysis of portuguese SMEs", Master thesis, Universidade Técnica de Lisboa.

19. OECD. (2010), Guidance on Sustainability Impact Assessment. OECD Publishing, Paris.

20. Pereira, D., Leitão, J. C. (2013), Restructuring in SMEs, European Foundation for the Improvement of Living and Working Conditions, Loughlinstown.

21. PORDATA. (2020), "Pequenas e médias empresas em \% do total de empresas: total e por dimensão" (Small and medium-sized enterprises as a\% of total enterprises: total and by size), available at: 
https://www.pordata.pt/Portugal/Pequenas+e+m\%C3\%A9dias+empresas+em+percenta gem+do+total+de+empresas+total+e+por+dimens\%C3\%A3o-2859 (Januar 30, 2020)

22. Pradeep, M. D., Kuckian, A. S. A. (2017), "Going green in business-a study on the ecofriendly initiatives towards sustainable development in India going green in business - a study on the eco-friendly initiatives towards sustainable development in India', Research gate, Vol. 1, No. 2, pp. 40-50.

23. Rashidi, K., Cullinane, K. (2019), "Evaluating the sustainability of national logistics performance using data envelopment analysis', Transport Policy, Vol. 74, pp. 35-46.

24. Sharma, N. (2016), "Innovation in green practices: a tool for environment sustainability and competitive advantage', available at:

https://papers.ssrn.com/sol3/papers.cfm?abstract_id=2861530 (Januar 30, 2020)

25. Silva, A., Alves, W., Rodrigues, H. S. (2019), Level of implementation of lean manufacturing tools: a case study in the North of Portugal. In 15th International Symposium on Operational Research SOR' 19, 25-27 September, Slovenian Information Society, Slovenia, pp. 605-610.

26. Thorlakson, T., De Zegher, J. F., Lambin, E. F. (2018), "Companies' contribution to sustainability through global supply chains', Proceedings of the National Academy of Sciences of the United States of America, Vol. 115, No. 9, pp. 2072-2077.

27. Varela, L., Araújo, A., Ávila, P., Castro, H., Putnik, G. (2019), "Evaluation of the relation between lean manufacturing, industry 4.0, and sustainability', Sustainability, Vol. 11, No. 5, 1439.

28. World Commission on Environment and Development. (1987), Our common future, Oxford University Press, Oxford.

29. Yildiz Çankaya, S., Sezen, B. (2019), "Effects of green supply chain management practices on sustainability performance", Journal of Manufacturing Technology Management, Vol. 30, No. 1, pp. 98-121. 


\section{About the authors}

Wellington Alves is a Scientific Researcher at the Algoritmi Research Centre (SINOVPROC Project) from University of Minho. He is also Assistant Professor at Business School of the Polytechnic Institute of Viana do Castelo. Received his Ph.D. degree in Industrial and Systems Engineering from University of Minho, in 2018, with work in Evaluation of Sustainability in the Mining Sector. Participated in several international conferences, under a Science Without Boarders Grant. He is author of several publications, in international conferences and in scientific journals. Currently he performs scientific research in the areas of sustainability, social innovation, circular economy and green Logistics. The author can be contacted at wellingtonalves@esce.ipvc.pt

Ângela Silva, PhD, is Adjunct Professor at the Business School at Instituto Politécnico de Viana do Castelo, Portugal. She holds a Ph.D. in Engineering of Production and Systems from School of Engineering, University of Minho. She develops her research work in the COMEGI Research Center, in Operations Management and Logistics and also Modelling and Optimization of Energy Systems. At the University of Minho she is a researcher at the ALGORITMI Research Center in the "Industrial Engineering and Management (IEM)" research line, group of "Ergonomics and Human Factors (EHF)". Currently, she supervises Ph.D. and MSc projects in these areas, being a co-author of several scientific papers published in International Journals and Conferences. The author can be contacted at angela.a@esce.ipvc.pt

Helena Sofia Rodrigues, Ph.D. is an Adjunct Professor at the Business School at Instituto Politécnico de Viana do Castelo, Portugal. She received PhD in Applied Mathematics at University of Aveiro with the dissertation thesis "Optimal Control and Numerical Optimization Applied to Epidemiological Models". Her main research interests are optimal control, epidemiological models, numerical optimization and modelling. She is actively engaged in science projects (European COST ACTION 16227, Portuguese FCT - Fundação para a Ciência e Tecnologia through UIDB/04106/2020 and UIDP/04106/2020 and FONDOCYT - National Research, Science and Technology Fund of Dominican Republic). The author can be contacted at sofiarodrigues@esce.ipvc.pt 